\title{
Desenvolvimento Rural e Reconhecimento: tensões e dilemas envolvendo o Pronaf ${ }^{1}$
}

\author{
Cátia Meire Resende² e Rennan Lanna Martins Mafra ${ }^{3}$
}

Resumo: Este artigo objetiva investigar como o Pronaf é definido e avaliado pelo Estado brasileiro a fim de desconstruir qualquer relação de causalidade entre desenvolvimento e reconhecimento que possa existir nas informações sobre o Programa. A metodologia utilizada constitui-se por revisão de literatura e pela pesquisa de dados oficiais sobre o Pronaf, a qual orientou os questionamentos sobre o volume de recursos disponibilizado para o crédito, bem como sobre a distribuição destes entre os grupos de beneficiários e as regiões do País. Como principais resultados, evidencia-se que apenas a redistribuição dos recursos não é suficiente para o reconhecimento dos agricultores.

Palavras-chaves: Agricultura familiar; Pronaf; Reconhecimento; Desenvolvimento rural.

\begin{abstract}
This article aims to investigate how Pronaf (National Program for the Strengthening of Family Farming) is defined and assessed by the Brazilian government in order to deconstruct any causal relationship between development and recognition that may exist in the information about the program. The methodology used was a review of official data on Pronaf, which directed the questions about the volume of funds available for credit, as well as on the distribution of these between groups of beneficiaries and regions in Brazil. As main results, it is highlighted that only the redistribution of resources is not sufficient for the recognition of farmers.
\end{abstract}

Key-words: Family farming; Pronaf; Recognition; Rural development.

Classificação JEL: D33, H11, Z13.

1. Data de submissão: 24 de junho de 2015. Data de aceite: 17 de fevereiro de 2016.

2. Mestranda em Extensão Rural. Universidade Federal de Viçosa. Viçosa, Minas Gerais - Brasil. E-mail: catialadeira@yahoo.com.br

3. Professor do Departamento de Comunicação Social. Universidade Federal de Viçosa. Viçosa, Minas Gerais - Brasil. E-mail: rennan.mafra@gmail.com 


\section{Introdução}

A expressão "agricultura familiar" surgiu no Brasil num cenário de grandes reivindicações de movimentos sociais ligados ao campo e numa proposta de um Estado que buscava aperfeiçoar sua relação com a sociedade, a partir de um horizonte democrático. Logo, essa expressão se consolidou no País, através da criação do Programa Nacional de Fortalecimento da Agricultura Familiar, por meio do qual os sujeitos rurais então supostamente excluídos de uma relação explícita com o Estado, identificados na ampla categoria de agricultores familiares ${ }^{4}$, teriam acesso ao crédito agrícola e ao apoio institucional para o desenvolvimento de suas atividades (SCHNEIDER, 2003).

Assim, o Pronaf foi criado em 1996, no governo do presidente Fernando Henrique Cardoso, com o objetivo de "promover o desenvolvimento sustentável do segmento rural constituído pelos agricultores familiares, de modo

4. A expressão Agricultura Familiar foi institucionalizada através da criação da Lei n. 11.326, de 24 de julho de 2006, que aponta os seguintes critérios para a definição do agricultor familiar: I - não detenha, a qualquer título, área maior do que 4 (quatro) módulos fiscais; II - utilize predominantemente mão de obra da própria família nas atividades econômicas do seu estabelecimento ou empreendimento; III - tenha percentual mínimo da renda familiar originada de atividades econômicas do seu estabelecimento ou empreendimento, na forma definida pelo Poder Executivo; IV - dirija seu estabelecimento ou empreendimento com sua família (BRASIL, 2006). a propiciar-lhes o aumento da capacidade produtiva, a geração de empregos e a melhoria de renda" (BRASIL, 1996). Além disso, o Programa é considerado por alguns de seus estudiosos (MATTEI, 2010; NIEDERLE, 2014) "um indicativo de mudanças na orientação (ao menos no discurso) do governo em relação à agricultura e aos próprios agricultores" (CARNEIRO, 1997, p. 70). ao eleger como seus protagonistas uma categoria que até então se encontrava excluída das políticas governamentais.

No momento de sua criação e difusão, o Pronaf defendeu a promoção de um desenvolvimento rural sustentável que considerou, além do desenvolvimento econômico, diversos outros âmbitos da vida social, como a educação, a preservação ambiental e a participação dos agricultores no processo de formulação da política. Grisa (2012) aponta que o Programa, mais do que uma política de crédito rural, nasceu, em suas linhas de atuação, como uma política de desenvolvimento rural, voltada à promoção de infraestruturas e serviços básicos, além da capacitação de gestores políticos. Assim, podemos afirmar que o Pronaf se instituiu com vistas a superar a visão estritamente econômica e de modernização agrícola tão difundida até o momento de sua criação.

Nessa seara, podemos filiar o Programa às discussões contemporâneas sobre uma nova relação do Estado com os sujeitos, na qual a busca 
por reconhecimento se torna algo fundamental. Nesse sentido, diversos estudos admitem a ideia de que a criação do Pronaf esteve vinculada a uma noção de reconhecimento da especificidade dos agricultores familiares (CARNEIRO, 1997; SCHNEIDER et al., 2004; AQUINO e SCHNEIDER, 2010), atentando para um contexto socioeconômico no qual a agricultura se apresentava como grande geradora de divisas para o País, ao mesmo tempo em que os agricultores permaneciam carentes de políticas públicas que abarcassem suas particularidades.

$\mathrm{O}$ discurso da relação entre o Pronaf e o reconhecimento, no entanto, não se restringe ao debate acadêmico, uma vez que o reconhecimento dos agricultores familiares e a promoção do desenvolvimento rural sustentável também aparecem como "bandeira política" do Programa nos documentos oficiais que o analisam e o divulgam. Segundo o Relatório Ibase (2006), “a existência e a implementação do Pronaf, desde 1996, vem favorecendo o reconhecimento público da categoria social de agricultor(a) familiar, bem como sua expressão econômica e social na sociedade brasileira" (p. 8). Além disso, ao apresentar o Programa, a Cartilha de Orientação Pronaf (2013/2014), do Paraná, enfatiza que, graças a ele, "a agricultura familiar tem a sua disposição recursos para investir na propriedade, agregar tecnologia, melhorar a renda e planejar suas ações para a construção de um projeto de vida sustentável no meio rural" (p. 3), além de frisar que o Programa representa, para o agricultor, uma oportunidade para que "desenvolva seu projeto, realize seus sonhos e tenha melhor qualidade de vida" (p. 4).

Atualmente, a política do Pronaf se destaca pelos volumosos montantes de recursos destinados ao crédito e ao financiamento das atividades produtivas dos agricultores familiares, bem como pelo aumento significativo do número de agricultores beneficiados (RESENDE, 2014). No entanto, numa associação entre essa política pública e o reconhecimento, é válido ressaltar que um aprimoramento das condições de vida dos sujeitos, através do aumento na redistribuição dos recursos, não implica, automaticamente, no reconhecimento dos mesmos. Logo, o que esse artigo pretende desconstruir é a relação de causalidade existente entre desenvolvimento e reconhecimento no âmbito desta política pública. Dito por outras palavras, os esforços que aqui serão empreendidos pretendem apresentar a relação entre elementos do processo de desenvolvimento indicados na normatização do Programa e o alcance das medidas efetivadas, no intuito de evidenciar que a mudança estrutural na agricultura familiar brasileira, pretendida pelo Pronaf, não pode, por si só, ser associada ao reconhecimento.

Mesmo que o Pronaf tenha sido objeto de discussão e análise tanto no âmbito acadêmico quanto institucional, o debate entre o desenvolvimento e o reconhecimento não aparece como elemento central na maioria dos estudos que versam sobre o Programa. Isso pode ser constatado ao analisarmos o trabalho de Mattei (2010), que, ao mapear os estudos sobre o Pronaf entre 1996 e $2006^{5}$, revela a expressiva atenção acadêmica voltada a essa política em apenas dez anos de existência, mas demonstra que a temática do reconhecimento ou mesmo uma abordagem mais direcionada aos sujeitos não é privilegiada nesses estudos.

Numa rápida passagem por estudos científicos publicados em qualificados periódicos brasileiros, além de teses e dissertações disponíveis na internet ${ }^{6}$, também nos propomos a classificar alguns trabalhos disponíveis sobre o Pronaf, principalmente no que se refere à questão do desenvolvimento e do reconhecimento. Dessa forma,

5. Mattei (2010) catalogou 144 trabalhos sobre o tema, entre os quais estão artigos científicos, dissertações de mestrado, teses de doutorado e relatórios de pesquisa.

6. Para tais finalidades de composição introdutória da argumentação desse artigo, foram consultados, predominantemente, os periódicos Capes e a plataforma Scielo, buscando revistas que tratam sobre o tema, através de palavras-chaves como "Pronaf", "Reconhecimento" e "Desenvolvimento Rural", no período entre 2003 e 2014. Em seguida, todos os trabalhos coletados foram lidos e agrupados em abordagens argumentativas comuns. Por fim, foram escolhidos alguns estudos para representar as abordagens propostas. O objetivo dessa busca, no entanto, não é fazer um estudo sobre os periódicos e sim posicionar, de modo preliminar, um possível estado da arte acerca da pesquisa sobre o Pronaf no Brasil. 
esses trabalhos podem ser agrupados em três grandes abordagens.

Numa primeira abordagem, encontram-se estudos que descrevem a evolução do Programa, os quais, num caráter quantitativo, analisam os números disponibilizados ao longo dos anos. Longe de desconsiderar a importância destes trabalhos, que, dentre outras coisas, permitem que o Estado analise a distribuição da renda e perceba os rumos da política, é válido ressaltar que eles não problematizam o desenvolvimento para além de uma visão econômico capitalista. Dito por outras palavras, desenvolvimento corresponde a esforços de acumulação, de renda e de crédito, não apresentando, assim, uma relação com o reconhecimento, uma vez que, no aumento dos recursos, não está implícito que também haja o reconhecimento daqueles a quem ele supostamente atinge. Nesses trabalhos, as discussões privilegiam, em sua maioria, a distribuição e as fontes dos recursos (AZEVEDO e PESSÔA, 2011; CONTI e ROITMAN, 2011; SOUZA et al., 2013), o impacto do Programa sobre a produtividade dos agricultores beneficiados e as atividades financiadas (ALVES et al., 2006; MATTEI et al., 2007; GRISA et al., 2014; PEREIRA e NASCIMENTO, 2014) e o acesso ao crédito (BITTENCOURT, 2003; RODRIGUES, 2013).

Numa segunda abordagem, encontram-se os trabalhos que buscam estudar os beneficiários do Pronaf. Apesar de não questionarem criticamente a visão de desenvolvimento preconizada pelo Programa, esse grupo de estudos permite evidenciar a importância de se examinar os sujeitos a quem se destina a política pública e nos oferecem pistas sobre a relação entre $\mathrm{o}$ desenvolvimento e o reconhecimento. A partir das discussões sobre o uso que os beneficiários fazem dos recursos (TOLEDO, 2009; MERA e DIDONET, 2010; TOLENTINO, 2013), a dificuldade de acesso e de implementação do Programa (DOMINGUES, 2007; COPETTI, 2008), a participação nas tomadas de decisão sobre a formulação da política (BEDIN, 2005; OLIVEIRA et al., 2008), bem como a consideração das percepções e da diversidade desses agricultores (VIEIRA, 2007; SERENO, 2012; VARGAS, 2012), percebe- mos como o público-alvo do Programa deve ser pensado para além dos números que representam a abrangência da política e entendido como sujeitos de direito em busca do reconhecimento de suas especificidades.

Por fim, encontram-se estudos mais críticos que demonstram as contradições do Programa e questionam sua legitimidade. São estudos que tratam das situações de pobreza, exclusão e desigualdade social (TONNEAU et al., 2005; AQUINO e SCHNEIDER, 2010), problematizam a visão de desenvolvimento difundido pelo Programa (GAZOLLA e SCHNEIDER, 2005, 2013) e tratam das particularidades dos beneficiários (PEREIRA, 2003; COSTA, 2013). Neles, a temática do reconhecimento aparece sem, contudo, ser problematizada teórica e explicitamente nos casos empíricos. No entanto, esses estudos "abrem as portas" para que se problematize o potencial de reconhecimento dos sujeitos rurais por parte do Estado, a partir do Pronaf, assumindo que o reconhecimento não se faz presente apenas com uma política de desenvolvimento rural eminentemente redistributiva, sem uma consideração aos diretamente implicados em todo o processo de elaboração, implementação e avaliação.

Dessa forma, as discussões que se fazem presentes nesse artigo se aproximam da perspectiva crítica proposta pelos estudos da terceira abordagem apresentada, acrescentando ao debate a necessidade de relacionar o desenvolvimento e o reconhecimento, com vistas a desnaturalizar a relação de causalidade entre estes. De modo mais específico, esse artigo se propõe a problematizar o Pronaf a partir da discussão de que uma política de desenvolvimento rural, baseada na redistribuição dos recursos, não é capaz de promover o reconhecimento daqueles a quem se destina. Em última análise, investimo-nos da tarefa de demonstrar que o reconhecimento é de fundamental importância para a promoção de um desenvolvimento que dê conta das especificidades dos sujeitos e que não se limite à ótica capitalista de acumulação de riqueza.

O presente trabalho se realizou com base em revisão bibliográfica e em pesquisa documental, 
na qual foram revisitados dados de fontes oficiais como o Ministério da Agricultura, Pecuária e Abastecimento (Mapa), Ministério do Desenvolvimento Agrário (MDA), principalmente através dos Planos Safra da Agricultura Familiar, Instituto de Pesquisa Econômica Aplicada (Ipea), Banco Central do Brasil e Departamento Intersindical de Estatística e Estudos Socioeconômicos (Dieese) ${ }^{7}$.

Logo, esse artigo está estruturado em duas grandes seções, além desta introdução e das considerações finais. A primeira seção apresenta as mudanças em relação à visão sobre o meio rural, principalmente pelo Estado brasileiro, a fim de perceber esse espaço para além das relações econômicas. Em seguida, discute-se a noção de reconhecimento, entendendo-a como um processo complexo no qual os indivíduos buscam sua autorrealização. Na segunda seção apresenta-se dados gerais sobre o Pronaf, questionando as propostas de desenvolvimento e reconhecimento presentes na política, a fim de demonstrar como esta tem se efetivado em âmbito nacional. Além disso, discute-se, em última instância, a abrangência do Programa em relação aos seus beneficiários, a fim de compreender como tem se dado o acesso aos recursos dessa política de apoio aos agricultores familiares brasileiros.

\section{Desenvolvimento rural e reconhecimento da agricultura familiar}

Segundo Conterato (2008), até a década de 1990, os estudos direcionados ao meio rural privilegiaram as transformações tecnológicas e os efeitos da Revolução Verde sobre o processo produtivo. Durante o período de modernização da agricultura, frente às concepções de desenvolvimento baseado no crescimento econômico, diversos segmentos da sociedade foram atingidos pela noção de progresso. Logo, as ações voltadas ao

7. Os documentos consultados estão descritos na seção Referências. meio rural visavam o aumento dos índices de produtividade, tratando-o como um espaço destinado às atividades agrícolas.

No entanto, para Schneider (2010), essa situação começou a mudar com as transformações nas concepções sobre o desenvolvimento rural, as quais apresentam entre seus fatores decisivos os avanços em torno das discussões sobre a agricultura familiar e a crescente influência e ação do Estado no meio rural. Além disso, o autor destaca que as políticas de desenvolvimento rural no Brasil têm sido amplamente influenciadas pelos estudiosos do tema.

Dessa forma, Schneider e Gazolla (2011) destacam a necessidade de estudos que contemplem a agricultura familiar não apenas em sua diversidade e heterogeneidade, mas que investiguem como os agricultores constroem suas práticas, através das quais se fortalecem e se afirmam como agentes.

Nesse viés, Perondi e Schneider (2012) apontam a existência de correntes metodológicas que discutem a necessidade de se pensar o desenvolvimento rural sob outras perspectivas. Segundo os autores, após meio século de intervenções no meio rural, visando o seu desenvolvimento, os estudiosos e formuladores de políticas perceberam que o processo de mudanças sociais e econômicas não se restringia às transformações na base tecnológica da produção agrícola e na produtividade dos fatores e, assim, passaram a considerar o lugar dos atores sociais nesse processo.

Entre as propostas de mudança no enfoque sobre o desenvolvimento rural, pode-se elencar duas principais, as quais tomam os sujeitos como o centro da ação desenvolvimentista: a perspectiva orientada ao ator e a abordagem dos meios de vida.

De acordo com Long e Ploeg (2009), uma abordagem centrada nos sujeitos esteve, nos anos 1960 e início dos 1970, voltada à noção de que os diferentes padrões sociais podem se desenvolver sob as mesmas condições estruturais, ou seja, sem considerar que os indivíduos apresentam respostas diferentes às condições a que são submetidos, mesmo que essas pareçam similares. No 
entanto, para esses autores, a perspectiva orientada aos atores atualmente proposta apresenta a vantagem de se interessar em "explicar as respostas diferenciadas a circunstâncias estruturais similares" (p. 3). Dessa forma, os atores sociais não são vistos como "categorias sociais vazias" ou "recipientes passivos de intervenção", mas "como participantes ativos que processam informações e utilizam estratégias nas suas relações com vários atores locais, assim como com instituições e pessoas externas" (p. 3). Assim, os autores chamam a atenção para a necessidade de uma abordagem mais dinâmica para o entendimento das mudanças sociais, a qual evidencie a importância de fatores e relações internas e externas e reconheça o papel desempenhado pela ação e consciência dos sujeitos.

Para Deponti (2007), a perspectiva orientada ao ator surgiu como resposta às teorias que não acreditavam no poder de transformação do homem sobre sua própria realidade. Dessa forma, através do conceito de agência ${ }^{8}$, essa perspectiva considera o poder de ação do indivíduo sobre sua própria vida. Logo, em relação ao meio rural, a abordagem centrada no ator destaca a importância de valorizar a forma como os agricultores moldam os padrões do desenvolvimento agrário. Assim, parte-se do pressuposto de que os agricultores desenvolvem suas atividades a partir de distintas e específicas práticas, de acordo com seus próprios objetivos e experiências.

É nesse sentido que a abordagem dos meios de vida (livelihoods), proposta, entre outros autores, por Ellis (2000), pode ser considerada de fundamental importância para o entendimento das estratégias de sobrevivência dos sujeitos. Segundo Perondi (2007), discutir a abordagem dos meios de vida deixa claro que os agricultores familiares são capazes de realizar as melhores escolhas para a promoção do desenvolvimento rural e fortalecer esses meios "implicaria criar

8. "A noção de agência atribui ao ator individual a capacidade de processar a experiência social e de delinear formas de enfrentar a vida, mesmo sob as mais extremas formas de coerção" (DEPONTI, 2007, p. 6). mecanismos de diversificação ${ }^{9}$ das opções e estratégias de trabalho e renda, estimulando assim sua resiliência para lidar com crises, choques ou vulnerabilidade" (PERONDI e SCHNEIDER, 2012, p. 118). Entretanto, a aplicação de tal abordagem torna-se mais complexa. As opções de diversificação estão submetidas a contextos sociais conflituosos, nos quais a disputa por poder e por recursos não necessariamente se mostra explicitada. Assim, muitas vezes, a diversificação pode ser tomada como um discurso de criação de políticas de desenvolvimento, cujas práticas decorrentes não tenham sido o resultado da escolha dos agricultores envolvidos, mas, unicamente, de agentes externos ou de atores governamentais e/ou institucionais. Assim, não se pode crer que a diversificação seja algo absoluto: ela está submetida a contextos de interpretação e implementação, nos quais, muitas vezes, os sujeitos rurais não dispõem de poder e de informações suficientes para tomarem suas decisões e realizarem suas escolhas. Desse modo, não se pode afirmar que a diversificação, por si só, apresenta sempre as melhores escolhas e as disponibiliza para os agricultores; ou mesmo que a diversificação de atividades e políticas seria capaz de produzir um gesto crítico de estimular a resiliência para lidar com crises. Por isso mesmo, é preciso entender que a abordagem dos livelihoods não é suficiente para compreender as questões relativas ao desenvolvimento rural: este último deve ser problematizado em meio a contextos de interação nos quais sujeitos e instituições se constituem reciprocamente. Esse raciocínio se mostra necessário ainda mais no caso do Brasil em que, especificamente, apesar de não haver uma correlação direta entre essas abordagens e a ação pública, pode-se reconhecer um esforço do Estado em construir políticas públicas voltadas para o meio rural, a partir de uma perspectiva que não

9. "A diversificação torna-se um fator-chave do desenvolvimento na mesma medida em que o próprio desenvolvimento passa a ser considerado enquanto processo que possibilita aos atores sociais maior autonomia para construir as trajetórias de vida que consideram significativas" (NIEDERLE e GRISA, 2008, p. 50). 
toma esse meio apenas como espaço de produtividade (CONDRAF, 2010) ${ }^{10}$ - questão essa que, por si só, não é suficiente para gerar desenvolvimento. Apesar disso, ao reconhecer a existência de modos de vida diferenciados, os sujeitos presentes nesse espaço começam a ter seus direitos assegurados, através de políticas públicas que admitem suas especificidades. Logo, em relação à agricultura familiar, nas últimas décadas, reflexões analíticas e políticas têm sido realizadas a fim de rever o passado, pensar o presente e o futuro do segmento (NIEDERLE, 2014). Segundo Niederle (2014), uma das principais inovações do cenário agrário do Brasil tem sido a expansão das lutas por reconhecimento e direitos por parte dos agricultores familiares, visando a consideração de suas particularidades tanto por parte do Estado quanto da sociedade civil. Nesse sentido, tal posicionamento abre espaço para uma discussão entre desenvolvimento rural e reconhecimento.

\section{Axel Honneth e a teoria do reconhecimento}

A questão do reconhecimento tem se tornado, em tempos recentes, um elemento central para a interpretação dos problemas que atingem a sociedade, tanto nos países centrais quanto nos periféricos (LUCAS e OBERTO, 2010). Além disso, essa temática tem sido muito utilizada para retratar questões de identidade e diferença, através de estudos sobre as condições de grupos minoritários ou marginalizados da sociedade civil, como mulheres, negros e homossexuais (DIAS, 2012; AVRITZER e GOMES, 2013; BUNCHAFT, 2012).

10. De acordo com o Conselho Nacional de Desenvolvimento Rural Sustentável (Condraf), a Política de Desenvolvimento do Brasil Rural, pensada a partir de 2008, se apresenta como um divisor de águas em relação à concepção que considera o rural apenas em sua dimensão agrícola e concebido como "resíduo do urbano". Nesse sentido, a nova política de desenvolvimento rural procura abordar os três atributos básicos do meio rural: "espaço de produção, espaço de relação com a natureza e espaço de (re)produção de modos de vida diferenciados" (CONDRAF, 2010, p. 8).
Axel Honneth, um dos principais autores da teoria, entende o reconhecimento como a autorrealização dos sujeitos, a qual só é assegurada mediante o reconhecimento intersubjetivo da autonomia pessoal e das necessidades específicas de cada indivíduo (HONNETH, 2003). Logo, Mendonça (2009) destaca que, para alcançar a possibilidade de autorrealização, os sujeitos lutam por dignidade e pelo reconhecimento de suas particularidades e isso acontece tanto em esferas íntimas quanto em esferas públicas de interação social.

Para Honneth (2003), as lutas por reconhecimento são motivadas pelos conflitos morais, a partir do desrespeito às formas de reconhecimento mais elementares a que os indivíduos estão submetidos: o amor, o direito e a estima social, as quais permitem que os sujeitos construam relações de autoconfiança, autorrespeito e autoestima, respectivamente. No entanto, essas relações que o sujeito estabelece consigo mesmo só podem ser bem-sucedidas quando se relacionam ao reconhecimento intersubjetivo das capacidades e realizações dos indivíduos, uma vez que, para esse autor, não há autorrealização sem reciprocidade entre os atores sociais.

Para cada uma das formas de reconhecimento, Honneth (2003) estabelece uma forma de desrespeito ou de reconhecimento recusado. Como as formas de reconhecimento estão relacionadas à autorrealização dos indivíduos, o autor destaca que as reações negativas, como a vergonha e a ira, que sucedem a experiência de desrespeito revelam aos sujeitos que as formas de reconhecimento lhe estão sendo recusadas e podem resultar numa motivação na qual se baseia as lutas por reconhecimento. Nesse sentido, Mendonça (2009) aponta que, mesmo impedindo a autorrealização dos indivíduos, as formas de desrespeito permitem uma reflexividade, proveniente de uma indignação moral, produzindo lutas por reconhecimento, essenciais à evolução moral da sociedade, que se apresentam como possibilidades efetivas de transformação da realidade. 
Mendonça (2009) admite ainda a existência de críticas relacionadas à teoria do reconhecimento $^{11}$. No entanto, o autor defende que essas críticas não consideram que o reconhecimento é pensado como uma luta intersubjetiva. A ideia de luta sugere que o reconhecimento não pode ser concedido, alcançado ou doado, além de não estar restrito a fins específicos e não se limitar a conquistas de direitos garantidos pelo Estado, sendo um processo em que a sociedade, de maneira reflexiva, transforma os padrões de relação social. Ao mesmo tempo, a noção de uma luta que é intersubjetiva admite que ela somente pode ser construída numa relação com o outro e que os objetivos, estratégias e identidades não estão prontos, mas são resultado de uma ação conjunta.

Entre as críticas à teoria do reconhecimento, à maneira como esta foi formulada por Honneth, destaca-se internacionalmente as críticas da autora norte-americana Nancy Fraser, que contrapõe a noção de reconhecimento à proposta da redistribuição. Ao contrário de Honneth que admite o reconhecimento como uma categoria fundamental e a redistribuição como derivada deste, Fraser procura conciliar o reconhecimento e a redistribuição, defendendo que as demandas por justiça social se dividem em demandas redistributivas, visando uma distribuição mais justa de recursos, e demandas por reconhecimento que admitem as especificidades dos grupos minoritários, propondo, assim, uma concepção bidimensional da justiça (LUCAS e OBERTO, 2010).

Fraser (2002) defende que, ao optar por essa concepção bidimensional da justiça, torna-se desnecessário optar entre políticas de redistribuição e políticas de reconhecimento, podendo utilizar-se de uma política que abarque os dois aspectos. Como um argumento para essa defesa, a autora salienta que, num contexto nos qual se fazem presentes tanto as desigualdades econômicas quanto uma gama de diversidades culturais, "não é viável nem um economicismo redutor, nem um culturalismo banal" (p. 12). Assim, com o objetivo

11. O autor apresenta algumas das ideias de Fraser (2000, 2001, 2003) e Markell $(2000,2003,2006)$ que revelam críticas contra a teoria do reconhecimento. de incluir as reivindicações redistributivas e de reconhecimento, ela propõe o princípio de paridade de participação, no qual deve haver tanto uma distribuição dos recursos entre os sujeitos, garantindo independência e voz aos envolvidos, quanto padrões institucionalizados de respeito para que todos tenham oportunidades iguais de consideração social.

Ainda sobre as formulações dessa autora, é importante destacar que, ao defender a tese de que a justiça depende tanto da redistribuição quanto do reconhecimento, Fraser (2002) distingue duas formas de injustiças: a injustiça econômica, exemplificada pela exploração, marginalização econômica e privação, podendo ser solucionada pela redistribuição; e a injustiça cultural ou simbólica, confirmada nos padrões sociais de representação, interpretação e comunicação e exemplificada pela dominação cultural, ocultamento e desrespeito, e que pode ser resolvida a partir do reconhecimento.

Como remédios para essas injustiças, Fraser (2006) apresenta duas abordagens como formas de tratar a relação reconhecimento-redistribuição: a "afirmação" e a "transformação". Em relação às injustiças culturais, os remédios afirmativos se associam à revalorização da identidade de um grupo, deixando-a intacta em seu conteúdo e em sua relação com os demais grupos; os remédios transformativos, por sua vez, se referem a uma compensação do desrespeito por meio da "transformação da estrutura cultural-valorativa subjacente" (p. 237), elevando a autoestima dos membros desse grupo. No que se referem às injustiças econômicas, os remédios afirmativos interferem na má distribuição dos recursos, sem reestruturar as demais características do sistema produtivo; os remédios transformativos, por sua vez, são associados ao socialismo e, além de transformar a má distribuição dos recursos, provocaria uma mudança na estrutura do sistema de produção.

Ao travar um debate com essa autora, a qual acusa a teoria do reconhecimento de ser culturalista e de reduzir a desigualdade socioeconômica apenas à questão do reconhecimento, Honneth 
defende que o conceito de reconhecimento proposto não remete à cultura, mas às experiências morais dos sujeitos frente a seus parceiros de interação, sendo os conflitos morais, causados pelo desrespeito às formas mais elementares de reconhecimento, os motores para o desencadeamento das lutas por reconhecimento. Logo, para Honneth, os conflitos por redistribuição só ocorrem quando a situação dos sujeitos é considerada, por eles mesmos, injusta, sendo as lutas por redistribuição material também lutas por reconhecimento. Assim, Honneth reconstrói os conflitos sociais como lutas por reconhecimento "porque eles são desencadeados pelo sentimento de desrespeito que se segue da violação de expectativas bem fundadas de reconhecimento social" (BRESSIANI, 2011, p. 335).

Nesse sentido, numa tentativa de relacionar a teoria do reconhecimento e a agricultura familiar, temos que o reconhecimento dessa categoria vai muito além do simples reconhecimento institucional e burocrático. Pelo contrário, o reconhecimento dos agricultores familiares deve considerá-los em suas particularidades, para que os próprios agricultores possam se estimar enquanto portadores de direitos e sujeitos moralmente capazes de direcionar tanto seu espaço de produção quanto as demais dimensões de seu mundo particular. Logo, esse trabalho objetiva investigar o modo como o Pronaf é definido e avaliado pelo Estado brasileiro no sentido de desconstruir qualquer tipo de relação de causalidade entre desenvolvimento e reconhecimento que possa existir nas informações oficiais amplamente disseminadas sobre o Programa.

\section{Questionando o desenvolvimento e o reconhecimento no Pronaf}

De acordo com o Ipea (2007), a criação do Pronaf, em 1996, representou uma tentativa de fortalecimento da agricultura familiar e de promoção do desenvolvimento rural, significando a legitimação e o suposto reconhecimento, pelo Estado, de uma categoria social que até então havia sido ignorada e excluída dos benefícios das políticas públicas voltadas ao meio rural: os agricultores familiares. Logo, desde que foi lançado, o Programa permitiu maior destaque para a agricultura familiar tanto no que se refere aos resultados da aplicação do crédito quanto entre estudiosos e pesquisadores, tornando-se um programa de referência para tratar o desenvolvimento rural (AQUINO e SCHNEIDER, 2010).

A criação de um programa de fortalecimento da agricultura familiar parece colocar em xeque o modelo de modernização da agricultura adotado até então, em que a grande produção e a grande propriedade eram os setores privilegiados. Segundo Carneiro (1997), a ruptura com esse modelo é explícita no próprio texto do Pronaf, no qual se intenciona construir um "novo paradigma de desenvolvimento rural para o Brasil, sem os vícios do passado" (PRONAF, 1996, p. 14 apud CARNEIRO, 1997, p. 70), apresentando, ao menos teoricamente, um viés de desenvolvimento abrangente e includente, em que as especificidades e necessidades dos agricultores familiares tendem a ser reconhecidas e consideradas para a promoção do desenvolvimento rural.

Dessa forma, pode-se afirmar que a vinculação do Pronaf ao reconhecimento dos agricultores familiares tem suas origens na criação do Programa. No entanto, Mendonça (2009) afirma que o reconhecimento não visa promover a valorização de grupos específicos, uma vez que os sujeitos não devem ser reconhecidos por fazerem parte de determinado grupo social. Logo, para o autor, "a simples garantia de direitos não é a totalidade do reconhecimento" (p. 150), uma vez que os sujeitos precisam se sentir como capazes de serem estimados. Assim, o fato de uma política de desenvolvimento rural ser criada e destinada especificamente aos agricultores familiares não significa, consequentemente, que essa categoria foi valorizada e priorizada pelo Estado brasileiro.

Nesse sentido, apesar de apresentar, como bem afirma Tolentino (2013), "objetivos bem intencionados", o Pronaf foi alvo de diversas interpretações e questionamentos desde a sua constituição enquanto política pública de 
desenvolvimento rural. Logo, se faz necessário questionar a relação entre o modelo de desenvolvimento proposto pelo Programa e o modo como este foi implementado em todo o território brasileiro. Para tanto, é importante compreender se a maneira como o Programa tem se efetivado no País permite o reconhecimento de que meio rural se constitui de um espaço onde convivem múltiplas atividades e atores, além do reconhecimento dos agricultores familiares em suas especificidades.

A primeira versão do Programa sugere a promoção de um desenvolvimento sustentável, associando capacidade produtiva e melhoria na qualidade de vida. No entanto, conforme apontado por Carneiro (1997), a noção de sustentabilidade que acompanha o conceito de desenvolvimento não se sobrepõe ao aumento da capacidade produtiva e de renda, não havendo um rompimento com a noção de desenvolvimento atrelada aos aspectos econômicos. Para a autora, apesar dos avanços, "as metas anunciadas nos remetem à velha fórmula desenvolvimentista: aumento da produção $=$ diminuição de preço no mercado = competitividade" (p. 76). Além disso, os apontamentos de Tolentino (2012) chamam a atenção para o produtivismo agrícola presente no texto do decreto de criação do Pronaf. A utilização de expressões como aumento de sua capacidade produtiva, aumento da produtividade do trabalho agrícola e melhor desempenho produtivo (BRASIL, 1996) demonstrava como o meio rural estava fortemente vinculado ao setor agrícola e a maneira com que a questão da produtividade se sobrepunha aos demais objetivos do Programa.

Os dados gerais do Pronaf demonstram como as ações do Programa estiveram fortemente relacionadas ao aumento do volume de recursos destinados ao financiamento das atividades produtivas dos agricultores familiares. O montante de recursos passou de R\$ 93 milhões, em 1995 (MATTEI, 2005), para R\$28,9 bilhões em 2015 (PLANO SAFRA, 2015/2016). Além disso, o número de municípios atendidos pelo crédito financiado pelo Programa aumentou significativamente, passando de 3.403, em 1999/2000 (MDA, 2015) para 5.462, em 2013/2014 (MDA, 2015) e também se vê um grande aumento no número de contratos, passando de 802.849, em 1999 (RESENDE, 2014) para quase 1,9 milhão, no período 2014/2015 (MDA, 2015).

Nesse sentido, de acordo com Aquino e Schneider (2010), deve-se considerar que os incentivos da política de crédito do Pronaf têm se voltado mais a aumentar o número de contratos assinados a cada ano do que desenvolver métodos para avaliar os coeficientes de transformação das realidades em que os recursos são inseridos. Além disso, o destino dos recursos tem demonstrado que há uma desconsideração da diversificação das atividades e maior financiamento das atividades relacionadas ao agronegócio exportador. Isso pode ser comprovado quando Gazolla e Schneider (2013) analisam os produtos que recebem maiores investimentos pelo Pronaf, uma vez que há um explícito privilégio das lavouras de grãos e commodities agrícolas ${ }^{12}$. Para Mattei (2005), isso significa que o programa tem se preocupado mais com "atividades anuais de rotina", como as safras agrícolas, do que com a melhoria da produtividade dos sistemas de produção que necessitam de intervenções, como as atividades realizadas pelos agricultores familiares. Já segundo o Ipea (2008), isso se deve ao fato de que o programa "não tem sido pensado para contrapor-se à lógica dominante da produção agropecuária do País, cada vez mais pautada na especialização produtiva com base no uso de insumos modernos" (p. 195).

Nesse viés, é possível relacionar essa característica do Pronaf a uma política redistributiva de caráter afirmativo, conforme as colocações de Fraser (2002), uma vez que o Programa parece "tentar" diminuir a desigualdade no campo,

12. Gazolla e Schneider (2013) observaram a tendência de financiamento das lavouras de grãos e commodities agrícolas pelo Pronaf tanto em suas pesquisas na região Sul, especificamente no Rio Grande do Sul, quanto no restante do Brasil, com base nos dados do Bacen (2009 apud EBINA e MASSUQUETTI, 2010). Dessa forma, os autores apontam que os cultivos de milho $(36,25 \%)$, soja $(21,30 \%)$ e café $(11,91 \%)$ estão entre os mais financiados. 
através do acesso ao crédito por agricultores familiares, mas não modifica as estruturas de produção vigentes, as quais, no meio rural brasileiro, ainda estão baseadas, principalmente, na expansão do agronegócio. Segundo Fraser (2006), mesmo que a redistribuição afirmativa vise compensar a injustiça econômica, quando as estruturas são mantidas, há ainda uma desvantagem entre as classes. Assim, a classe mais desprivilegiada tende a ser marcada como "deficiente e insaciável". Logo, "uma abordagem voltada para compensar injustiças de distribuição pode acabar criando injustiças de reconhecimento" (p. 238).

Diante disso, vale ressaltar ainda que os recursos do Pronaf apresentaram uma má distribuição entre as regiões do País. Segundo dados da SAF/MDA, citados por Abramovay e Veiga (1999) e Mattei (2005), a região Sul do País apresentou grande concentração tanto dos contratos (78\%) quanto dos recursos (65\%), em detrimento das demais regiões brasileiras ${ }^{13}$, demonstrando um desequilíbrio espacial na primeira fase do Programa. Ao longo dos anos, esse desequilíbrio diminuiu, porém não foi superado, e os dados da distribuição regional dos recursos demonstram que, em 2004, a região Sul deteve 38,5\% dos contratos, a Nordeste, $36 \%$, a Sudeste, $14 \%$, a Norte, $7,5 \%$ e a Centro-Oeste, $4 \%$ (MATTEI, 2005), sendo essa tendência também confirmada no que se refere ao volume de recursos destinados ao Programa: em 2007, 43,72\% do crédito do Programa estava concentrado na região Sul, enquanto as regiões Sudeste, Nordeste, Norte e Centro-Oeste, detinham 22,17\%, 19,97\%, 7,39\% e $6,75 \%$, respectivamente.

Essa concentração fica ainda mais evidente quando se analisa o número de estabelecimentos considerados familiares em cada uma das grandes regiões brasileiras. O Censo Agropecuário de 2006, divulgado pelo IBGE, apresenta a região Nordeste como a região que detém o

13. "As demais regiões tiveram o seguinte desempenho: Norte, com 3\% dos contratos e 10\% dos recursos; Nordeste, com $13 \%$ dos contratos e $13 \%$ dos recursos; Sudeste, com 5\% dos contratos e $10 \%$ dos recursos; e Centro-Oeste, com $1 \%$ dos contratos e $2 \%$ dos recursos" (MATTEI, 2005, p. 19). maior número de estabelecimentos familiares $^{14}$ (2.187.295), seguida da região Sul (849.997), Sudeste (699.978), Norte (413.101) e, por último, da região Centro-Oeste (217.531). No entanto, vê-se que, para a região Nordeste foram destinados, no Plano Safra 2011/2012, de acordo com Peixoto (2011), R\$ 3,5 bilhões e, para a região Sul, o montante de $\mathrm{R} \$ 7,1$ bilhões, enquanto que as demais regiões receberam $\mathrm{R} \$ 3,4$ bilhões, R \$ 1 bilhão e R\$1,28 bilhão, respectivamente.

Vale destacar que os critérios de seleção dos beneficiários do Pronaf, conforme veremos adiante, podem ser considerados como grandes colaboradores para a concentração dos recursos do Programa na região Sul do Brasil, uma vez que essa região contava com um grande nível de organização dos agricultores, além de possuir agroindústrias de grande peso econômico, que facilitavam um processo de integração produtiva dos mesmos (MATTEI, 2007). Essa concentração dos recursos na região Sul também pode ser vinculada à terceira forma de reconhecimento recíproco proposta por Honneth (2003): a estima social, uma vez que os agricultores sulistas parecem apresentar maior estima social e maior demanda moralmente motivada, se organizando como interlocutores e, assim, se sentindo mais "reconhecidos" que os demais agricultores familiares brasileiros.

Essa disparidade entre a atuação do Pronaf principalmente entre as duas regiões que apresentam o maior número de estabelecimentos familiares do País vai em direção oposta aos princípios que nortearam a criação do Programa, principalmente no que se refere à promoção de um desenvolvimento rural sustentável. Aquino e Schneider (2010) salientam que, na região Nordeste, o financiamento é deficiente no que se refere ao reconhecimento da diversidade das atividades das famílias de agricultores, bem como o Programa ainda estimula o exercício de atividades agropecuárias vulneráveis às secas, não incentivando a implantação de tecnologias alternativas para as

14. Os estabelecimentos são denominados familiares em consonância aos critérios de classificação dos agricultores familiares definidos pela Lei n. 11.326, de 2006. 
atividades no espaço do semiárido. Na região Sul, o mesmo tem se verificado nas ações da política, a qual se norteia pelo modelo de desenvolvimento baseado no produtivismo, com o incentivo à produção de grãos e commodities agrícolas, como o milho e a soja, utilizando-se de insumos agrícolas que prejudicam o meio ambiente.

Nessa seara, temos que a forma de operacionalização do Pronaf tem se baseado no aumento significativo do volume de recursos investidos no crédito destinado aos agricultores familiares. No entanto, esse aumento dos recursos não significa que o Programa esteja apresentando uma visão de desenvolvimento rural voltada aos sujeitos, visto que é possível afirmar que uma maior distribuição de recursos meramente financeiros não tem como consequência lógica nem a melhoria nas condições de vida desses indivíduos nem a certeza de que suas aspirações estão sendo atendidas. É necessário que a distribuição dos recursos adentre os contextos de interação dos agricultores familiares e que seja acompanhada de uma fiscalização e orientação sobre a utilização desses recursos. Além disso, como os dados mais gerais do Pronaf bem demonstraram, não é um fato que esses recursos têm chegado a todos os agricultores de maneira homogênea, recriando a lógica mercadológica e capitalista de desenvolvimento, na qual os sujeitos que possuem mais recursos se sobressaem sobre os menos favorecidos.

\section{Beneficiários do Pronaf: reconhecimento por práticas redistributivas?}

No caminho de buscar a desconstrução da relação de causalidade entre o desenvolvimento e o reconhecimento, as informações gerais sobre o Pronaf demonstram como a política tem se operacionalizado em âmbito nacional. Nesse viés, se faz pertinente a utilização dos dados para analisar como tem se efetivado o acesso dos agricultores familiares a essa política e, assim, refletir se e de que forma o reconhecimento dos agricultores tem se concretizado.
Segundo Tolentino (2013), para a definição do público alvo do Pronaf, em sua formulação, foram utilizados os estudos FAO/Incra (1995, 1996), nos quais estabeleceu-se uma distinção entre a agricultura familiar e a agricultura patronal, utilizando o critério do tipo de mão de obra utilizada nos estabelecimentos. $\mathrm{O}$ trabalho assalariado foi considerado como característico da agricultura patronal e o trabalho familiar, da agricultura familiar. Assim, o autor apresenta a definição de três grupos de agricultores familiares. São eles: agricultores consolidados, aqueles integrados ao mercado e que possuem acesso às políticas públicas e inovações tecnológicas; agricultores em transição, integrados de maneira parcial ao mercado e aos circuitos tecnológicos, fato este que favorece sua viabilidade econômica; e agricultores periféricos, grupo mais numeroso, porém considerado como não viável do ponto de vista econômico.

Através dessa classificação, o Pronaf se destinava apenas aos agricultores em transição, o que, de acordo com Carneiro (1997), evidencia um caráter excludente do Programa em relação a seu público-alvo, uma vez que, ao alegar que estes apresentavam maior viabilidade econômica, se excluía aproximadamente 11 milhões de pessoas, classificadas como agricultores familiares periféricos.

Para Carneiro (1997), os critérios para a definição de beneficiários do Pronaf, quando da sua criação, construíram a noção do "verdadeiro agricultor", o qual seria aquele, de inclinação empresarial, adequado para encontrar na atividade agrícola toda, senão em grande parte, da renda familiar. Porém, instituir o "bom" agricultor como aquele que obtém sua renda da atividade agrícola desconsidera que a combinação da agricultura com outras fontes de renda pode ser indispensável à continuidade da própria atividade agrícola e da retenção da mão de obra no campo.

Ao longo dos anos, as transformações ocorridas no Pronaf, baseadas principalmente no aumento significativo dos recursos destinados ao crédito, se deram no intuito de ampliar seu público-alvo e se tornar uma política de caráter descentralizado e participativo. Assim, sob a 
coordenação do Mapa (Ministério da Agricultura, Pecuária e Abastecimento), a partir da Linha Infraestrutura e Serviços Municipais, foram criados os Conselhos Municipais de Desenvolvimento Rural (CMDR).

Segundo Abramovay (2001), esses conselhos representam uma inovação organizacional significativa, uma vez que os recursos de um programa do governo federal passam pela mediação de representantes locais. Nesse viés, entende-se que a criação dos CMDR pode ser considerada indício de que houve um reconhecimento da importância da participação, na formulação e aplicação da política pública, daqueles que são os principais beneficiários dela: os agricultores familiares. Além disso, tem-se a criação desses conselhos inserida em uma das formas de reconhecimento propostas por Honneth (2003): o reconhecimento jurídico.

Honneth (2003) salienta que, a partir das primeiras décadas do século XX, "dá-se o momento em que se impôs definitivamente a convicção de que todo membro de uma coletividade política deve caber o direito igual à participação no processo democrático de formação da vontade" (p. 191). Logo, para o autor, os direitos políticos de participação e os direitos sociais de bem-estar surgem a partir da ampliação, forçada "a partir de baixo", da ideia de "igualdade de valor" de todos os membros de uma coletividade política.

Logo, podemos entender que, em relação à criação dos CMDR no âmbito da política do Pronaf, "a partir de baixo" se relaciona ao fato de que essa política pública seria supostamente gerida a partir das demandas dos agricultores familiares que, após se reconhecerem como sujeitos de direito, expressarão suas vontades. Somado a isso, temos a ideia de "igualdade de valor" entendida a partir da concepção de que todos os cidadãos possuem os mesmos direitos e, por isso, são iguais perante à lei, ou seja, no âmbito do CMDR, tanto os representantes dos agricultores quanto os das instituições terão o mesmo "valor", podendo se expressar através da garantia de que serão ouvidos igualmente. A partir daí, tendo os direitos políticos de participação efetivados, os direitos sociais de bem-estar seriam consequência desse processo, uma vez que Honneth (2003) evoca que, "um sujeito é respeitado se encontra reconhecimento jurídico não só na capacidade abstrata de poder orientar-se por normas morais, mas também na propriedade concreta de merecer o nível de vida necessário para isso" (p. 193).

Além de relacionar a criação dos CMDR às formulações de Honneth (2003), temos ainda a relação entre os conselhos e o princípio de paridade de participação, proposta por Fraser (2002). Dessa forma, a criação dos CMDR se dá de maneira a conciliar a política de crédito do Programa, de caráter distributivo, à participação dos agricultores familiares no processo de implantação da política, o que se vincula ao reconhecimento dessa categoria.

No entanto, o caráter burocrático dos conselhos, uma vez que são criados para atender às exigências legais para obtenção de recursos públicos, a limitação da capacidade de representação das demandas coletivas por parte dos agricultores e a escala de atuação dos conselhos, já que, no plano municipal, a utilização dos recursos do Pronaf se limita a suprir deficiências básicas dos municípios (ABRAMOVAY, 2001) permitem inferir que há uma maior preocupação com a redistribuição dos recursos do que com o reconhecimento das especificidades dos agricultores e das realidades locais e a promoção do desenvolvimento rural.

Como afirmado anteriormente, o Pronaf sofreu inúmeras alterações ao longo do tempo. Segundo o Ipea (2007) algumas dessas transformações foram resultado das pressões dos movimentos sociais ligados ao campo, os quais pretendiam adequar os mecanismos do Programa à diversidade de situações existentes no meio rural, incorporando os segmentos mais pobres e menos assistidos da agricultura familiar. Dessa forma, tem-se uma luta por reconhecimento por parte dos movimentos sociais e dos agricultores familiares que reivindicavam as mudanças no Programa. Essa ideia é confirmada a partir das formulações de Honneth (2003), que, apresentando a forma de reconhecimento recíproco baseado na estima social, afirma que quanto mais 
os movimentos sociais conseguem chamar a atenção da esfera pública para a causa que defendem, maior a possibilidade de elevar na sociedade o valor social e a reputação dos seus membros. Além disso, o autor aponta que, como as relações de estima social estão indiretamente relacionadas à distribuição da renda, "os confrontos econômicos pertencem constitutivamente a essa forma de luta por reconhecimento" (p. 208).

Na busca pela ampliação dos beneficiários do Programa, foram criados, em 199915, quatro diferentes grupos (A, B, C e D), com base na renda bruta anual das famílias. Segundo Mattei (2007, p. 146), o grupo A incluía os agricultores assentados pelo processo de reforma agrária; o grupo $\mathrm{B}$, os agricultores com baixa produção e pouco potencial de aumento da produção; o grupo C, os agricultores com exploração intermediária, mas com bom potencial de resposta produtiva; e o grupo D, os agricultores estabilizados economicamente.

Essa classificação sofreu diversas alterações, baseando-se no aumento do limite da renda dos agricultores. No Plano Safra 2000/2001 foi criado o grupo $\mathrm{A} / \mathrm{C}$, que se refere aos assentados (grupo A) já beneficiados com o crédito de instalação (grupo C) e no Plano Safra 2003/2004, o grupo E, composto por agricultores familiares com os melhores índices de renda bruta familiar anual, foi incluído à classificação, totalizando seis grupos de beneficiários (MATTEI, 2007).

Por meio dessa classificação, o limite de renda sofreu grandes alterações entre os grupos: enquanto em 1999 o limite máximo de renda era de $\mathrm{R} \$ 27.500$, em 2004, esse valor chegou a R\$ 60 mil. No entanto, a distribuição dos contratos e dos recursos também se mostrou de maneira desigual entre as diferentes categorias. Mattei (2007) aponta que, em 1999, os agricultores do grupo A responderam por $65 \%$ dos contratos e $46 \%$ dos recursos, enquanto que os agricultores do grupo D detiveram $28 \%$ dos contratos e $50 \%$ dos recursos, demonstrando que o maior

15. Resolução n. 2.629, de 10 de agosto de 1999 (BANCO CENTRAL DO BRASIL, 2013). volume de recursos se destinou aos agricultores já consolidados. Já em 2004, os grupos A, B, C e D responderam por $6 \%, 72 \%, 10 \%$ e $11 \%$ dos contratos, respectivamente, enquanto que em relação aos recursos os percentuais chegaram a $20 \%$, $18 \%, 18 \%$ e $36 \%$. Esses dados demonstram que, apesar da diminuição da participação dos grupos de agricultores que se encontram mais consolidados (C, D e $\left.E^{16}\right)$, a soma de suas participações ainda indica uma tendência de beneficiamento do segmento dos agricultores familiares mais consolidados.

Vale ressaltar que o Plano Safra 2007/2008 trouxe uma grande mudança nos grupos de beneficiários do Pronaf, uma vez que, a partir de $1^{\text {o }}$ de julho de 2008, os grupos C, D e E deixaram de existir, unindo-se em um só grupo denominado "agricultores familiares", ou o grupo AF, além do aumento no limite de renda para R 110 mil. A criação do grupo AF evidenciou ainda mais a concentração dos recursos entre os agricultores mais capitalizados. Em 2007, o grupo D detinha 39,84\% do montante do crédito rural do Programa, enquanto que os grupos E, C, B, A e A/C detinham 19,99\%, 15,19\%, 6,22\%, 3,72\% e $0,34 \%$, respectivamente ${ }^{17}$. Isso indica que, apesar da evolução do Pronaf, em 2007, os maiores beneficiários do Programa ainda eram os agricultores mais capitalizados (grupo D e E) e os produtores em transição (grupo C), os quais ofereciam maiores garantias aos bancos ${ }^{18}$ (AQUINO, 2009). Logo, é possível reconhecer que a ampliação tanto dos recursos, como vimos, quanto do limite da renda não significaram a ampliação do público atendido, uma vez que os contratos permaneceram concentrados nos segmentos C, D e E, indicando uma tendência de direcionamento do Programa

16. É importante ressaltar que o grupo E somente foi incluído nos grupos de agricultores familiares beneficiados em 2003. Nas estatísticas citadas, a participação do grupo E em 2004 é de $1 \%$ do número de contratos e $8 \%$ dos recursos.

17. Dados retirados de Aquino (2009), segundo Ipea (2007) e MDA (2009). A categoria denominada "Outros" recebeu, em 2007, 14,69\% do montante do crédito rural do Pronaf.

18. Segundo o Ipea (2012), os maiores índices de inadimplência do Pronaf estão entre os segmentos A e B. 
aos grupos mais capitalizados da agricultura familiar.

Em relação à criação do grupo $\mathrm{AF}$, Tolentino (2013) questiona se estaria havendo uma mudança no discurso da política ao estabelecer distinções tão nítidas entre os agricultores do grupo $\mathrm{B}$, que produziam basicamente para o consumo próprio, e agricultores dos segmentos C, D e E, os quais já se encontravam integrados ao mercado agroindustrial. Essas indagações também são colocadas no Boletim do Ipea (2010), o qual estabelece que a junção dos três últimos segmentos tende a negar a diversidade da agricultura familiar brasileira, além de prejudicar o monitoramento do desempenho do programa de acordo com seus grupos. Além disso, a denominação do novo grupo como Agricultores Familiares permitiu questionamentos sobre a negação dos demais grupos enquanto membros dessa categoria ${ }^{19}$.

De acordo com o Ipea (2014), desde sua criação, o Pronaf tem baseado suas ações na ampliação dos limites de renda de enquadramento dos agricultores familiares, além do aumento dos valores dos empréstimos e da redução das taxas de juros, resultando no aumento do valor médio dos empréstimos de investimento e na maior participação da região Sul e Sudeste no valor total dos financiamentos, uma vez que essas regiões apresentam o maior número de agricultores mais capitalizados. Além disso, o Boletim do Ipea aponta que os agricultores mais marginalizados, do grupo $\mathrm{B}$, se concentram na região Nordeste, enquanto os assentados da reforma agrária (grupo A) se encontram nas regiões Norte e Centro-Oeste.

Nesse sentido, o aumento no limite da renda dos agricultores familiares se tornou, apesar de outras medidas, a principal mudança ocorrida no âmbito do Pronaf ${ }^{20}$. Contudo, é preciso consi-

19. O Boletim do Ipea (2010) levanta as seguintes questões: "por que denominar a junção dos grupos CDE em "Agricultura Familiar"? Os demais grupos não pertencem à agricultura familiar? O grupo $\mathrm{B}$, por exemplo, que corresponde a mais da metade da agricultura familiar brasileira, não está sendo relegado a uma situação de subcategoria ou de público periférico não prioritário do Pronaf?" (p. 222).

20. O limite de renda divulgado pelo Plano Safra 2015/2016 chega a R\$ 360 mil. derar que a identificação dos grupos pelas faixas de renda apresenta o risco da redistribuição ser tomada como garantia de reconhecimento desses agricultores, resultando numa concentração ainda maior dos recursos entre os agricultores familiares já consolidados, mais propensos a acessar a lógica do mercado. Logo, a ampliação dos limites de renda, por um lado, não significa que o acesso à política tem aumentado, principalmente quando se trata de agricultores familiares de menor poder aquisitivo e, por outro, não representa que essa política adota uma perspectiva voltada aos agricultores e, sim, ao produtivismo e ao desenvolvimento baseado no aumento da renda.

Assim, é possível constatar que as práticas redistributivas, já questionáveis de um ponto de vista da relação do Estado com sujeitos rurais em situação de periferização, não podem ser indicadoras de um reconhecimento dos beneficiários dessa política. Dito por outras palavras, além de evidenciar problemas na operacionalização dos processos de desenvolvimento rural pelo Programa - com foco bastante centralizado nas questões financeiras -, não se pode, de forma nenhuma, considerar o aumento na oferta de recursos financeiros como indicativo de que há um desenvolvimento rural capaz de produzir reconhecimento. A constatação desse último fenômeno, portanto, refere-se, antes de tudo, a um gesto recíproco e intersubjetivo que deve nascer dos próprios agricultores acerca da valorização de suas especificidades, quanto, sobretudo, de práticas interacionais de reconhecimento de demais agentes e instâncias da sociedade - algo que, sem sombra de dúvidas, transcende a mera destinação de recursos nos contextos de desenvolvimento rural constituídos pelo Pronaf.

\section{Considerações finais}

A criação do Pronaf pode ser considerada um dos eventos de maior importância na esfera das políticas públicas para o meio rural, com foco nos agricultores familiares. Em seu discurso inicial, o 
Programa demonstrou-se como uma política de promoção de um desenvolvimento rural sustentável, passando a entender o meio rural como um espaço onde convivem múltiplas atividades e atores, desvinculando-o das bases essencialmente agrícolas. Além disso, o Programa ensejou reconhecer, ainda que discursivamente, as particularidades e necessidades dos agricultores familiares que, até então, estavam excluídos do cenário das políticas governamentais.

As análises dos dados gerais dessa política pública evidenciaram que a trajetória do Programa tem se baseado na ampliação do montante de recursos disponibilizados ao crédito rural, bem como o aumento do número de beneficiários, através da criação de grupos com base na renda anual das famílias. No entanto, essas análises demonstraram que a maior alocação de recursos do Programa não é suficiente para atender o objetivo principal de criação do Pronaf, ou seja, a diminuição da desigualdade no meio rural brasileiro. Além disso, a má distribuição dos recursos entre as regiões do País, bem como entre os grupos dos próprios agricultores familiares reflete a ineficácia do Programa ao promover um desenvolvimento que considera, ao mesmo tempo, o aumento da renda, a igualdade social e a valorização do meio ambiente.

A versão recente do Programa tem se apoiado em uma lógica evolucionista, que prioriza os segmentos mais capitalizados da agricultura familiar. Se no momento de sua criação, o Pronaf apresentou suas principais alterações devido às reivindicações dos agricultores familiares, que objetivavam adequar o Programa à diversidade da agricultura familiar (IPEA, 2007), agora, o governo cede à pressão dos grupos mais consolidados e organizados do meio rural, favorecendo seu acesso à política de crédito do Programa. Segundo Aquino e Schneider (2010), esse fato já era esperado, uma vez que, para os autores, o Pronaf "em nenhum momento de sua trajetória pretendeu atender os agricultores familiares de forma homogênea" (p. 11), já que foi criado para atender a um "tipo ideal" de agricultor, ou seja, os agricultores familiares mais integrados ao mercado.
É importante considerar que, no momento de sua criação, o Pronaf se apresentou como uma política de reconhecimento, que refletia as demandas da população rural. Porém, o modo como essa política tem se operacionalizado nos permite desconstruir a ideia de que um desenvolvimento redistributivo, baseado apenas no aumento da produtividade e da renda, é capaz de promover o reconhecimento daqueles que estão às margens do sistema capitalista de produção.

Souza (2003) aponta a dificuldade de relacionar, simultaneamente, reconhecimento e redistribuição a sujeitos que são relegados a uma situação de subcidadania e encarados sob a ótica de uma "ideologia de desempenho". Assim, o aumento dos recursos não implica, necessariamente, no reconhecimento dos agricultores marginalizados, sendo necessárias intervenções que considerem as particularidades dos sujeitos e suas aspirações quanto ao tipo de desenvolvimento que pretendem alcançar.

Nesse sentido, a principal conclusão desse trabalho é que, ainda que o Pronaf, sem sombra de dúvidas, tenha contribuído para a tematização pública da agricultura familiar, as análises nesse estudo, e em outros supracitados, não evidenciam que o mesmo tenha contribuído para o reconhecimento da agricultura familiar. Por mais contundente que essa afirmação se apresente, torna-se necessário explicitar esse raciocínio, uma vez que as questões relativas ao reconhecimento são complexas, envolvendo, para muito além da definição cognitiva de uma categoria de beneficiários, a constituição de um ciclo que envolva dimensões jurídicas, afetivas e sociais. Por outro lado, é a própria constituição do discurso de reconhecimento da agricultura familiar empreendido pelo Pronaf que permite verificar lacunas no que se refere ao reconhecimento dos agricultores familiares, bem como problematizar aspectos que possam vir, em experiências futuras, colaborar com o aprimoramento do Programa na direção ora proposta.

Todavia, para muito além disso, é necessário ponderar que, na dimensão concreta da experiência rural, inúmeras políticas públicas, a depender dos contextos, se apresentam de modo 
entrelaçado, fato que convoca, inevitavelmente, uma análise do reconhecimento dos agricultores familiares que transcenda o próprio Pronaf. De tal sorte, ainda que o foco desse artigo não tenha sido a discussão do reconhecimento dos agricultores familiares do meio rural como um todo, é extremamente instigante também indagar em que medida o Pronaf encabeçou outros programas e ações para o meio rural que contribuíram para o reconhecimento de inúmeros sujeitos dantes invisibilizados. Sendo assim, uma questão de pesquisa que merece ser investigada com acuidade, resultante das discussões aqui propostas, é indagar se a criação do Programa não oportunizou o reconhecimento dos agricultores familiares mais vulneráveis, ainda que tal reconhecimento possa ter se concretizado não unicamente pelo Pronaf, mas por meio de outras políticas públicas que surgiram em sequência e que coexistem na relação dos agricultores familiares com o Estado e com os contextos sociais imediatos que os acolhem.

De tal sorte, a realização de estudos de caso qualitativos, voltados a correlacionar os dados gerais aqui apresentados com inúmeros aspectos das relações entre Pronaf e sujeitos beneficiários, certamente oferece condições de ampliar as possibilidades de entendimento e de problematização acerca da relação entre reconhecimento, desenvolvimento e meio rural. Sendo assim, tal gesto mostra-se de extrema relevância para oferecer aprofundamentos em estudos futuros, na medida em que permite a verificação do reconhecimento em sua dimensão sempre contextualizada e produzida mediante processos reciprocamente constituídos, nos quais se inscrevem tanto possibilidades quanto limitações à autorrealização de inúmeros grupos e sujeitos sociais presentes no meio rural.

\section{Referências}

ABRAMOVAY, R. Conselhos além dos limites. Estudos Avançados, Dossiê Desenvolvimento Rural. São Paulo, USP, Volume 15, Número 43, 2001.
. e VEIGA, J. E. Novas instituições para o desenvolvimento rural: o caso do Programa Nacional de Fortalecimento da Agricultura Familiar (PRONAF). Texto para Discussão no 641. Brasília: FIPE/IPEA, 1999.

ALVES, E., SOUZA, G. S. e OLIVEIRA, C. A. V. Desempenho de estabelecimentos do Pronaf. Revista de Política Agrícola, Brasília, DF, Ano XV, no 4, 2006.

AQUINO, J. R. Avanços e limites da política de crédito do PRONAF no Brasil (1996-2008): uma reflexão crítica. In: XLVII Congresso da Sociedade Brasileira de Economia, Administração e Sociologia Rural, v. 1, p. 1-21, UFRGS, Porto Alegre, 2009.

. e SCHNEIDER, S. (Des)caminhos da política de crédito do Pronaf na luta contra a pobreza e a desigualdade social no Brasil rural. I Conferência Nacional de Politicas contra a Pobreza e a Desigualdade. Natal, 2010.

AVRITZER, L. e GOMES, L. C. B. Política de reconhecimento, raça e democracia no Brasil. Dados Revista de Ciências Sociais, Rio de Janeiro, v. 56, n. 1, 2013.

AZEVEDO, F. F. e PESSÔA, V. L. S. O Programa Nacional de Fortalecimento da Agricultura Familiar no Brasil: uma análise sobre a distribuição regional e setorial dos recursos. Sociedade e Natureza, Uberlândia, ano 23, n. 3, p. 483-496, 2011.

BANCO CENTRAL DO BRASIL. Resolução 2.629, de 10 de agosto de 1999. Disponível em: <www.bcb.gov. br/pre/normativos/res/1999/pdf/res_2629_v2_L.pdf > . Acesso em: dez. 2014.

BEDIN, O. L. Participação dos agricultores familiares no programa Pronaf modalidade Infra-estrutura: um estudo de caso no município de Tupãssi-PR. 2005. $75 \mathrm{f}$. Dissertação (Mestrado em Engenharia de Produção) - Programa de Pós-Graduação em Engenharia de Produção, Universidade Federal de Santa Catarina, Florianópolis. 2005.

BITTENCOURT, G. A. Abrindo a caixa preta: o financiamento da agricultura familiar no Brasil, 2003. 243 f. Dissertação (Mestrado em Desenvolvimento Econômico, Espaço e Meio Ambiente) - Instituto de Economia, Universidade Estadual de Campinas, Campinas, 2003.

BRASIL. Decreto n. 1.946, de 28 de junho de 1996. Cria o Programa Nacional de Fortalecimento da Agricultura Familiar - PRONAF e dá outras providências. Disponível em: <http://www.planalto.gov.br/ccivil_03/ decreto/D1946.htm >. Acesso em: dez. 2014.

. Lei 11.326, de 24 de julho de 2006. Estabelece as diretrizes para a formulação da Política Nacional da 
Agricultura Familiar e Empreendimentos Familiares Rurais. Disponível em: <http://www.planalto.gov.br/ ccivil_03/_ato2004-2006/2006/lei/111326.htm>. Acesso em: dezembro 2015.

. Ministério do Desenvolvimento Agrário, 2015. Disponível em: <www.mda.gov.br>. Acesso em: dez. 2014.

BRESSIANI, N. Redistribuição e Reconhecimento. Nancy Fraser entre Jürgen Habermas e Axel Honneth. Cadernos CRH, v. 24, n. 62, p. 331-352, 2011.

BUNCHAFT, M. E. A temática das uniões homoafetivas no Supremo Tribunal Federal à luz do debate HonnethFraser. Revista Direito GV, São Paulo, v. 8, n. 1, 2012.

CARNEIRO, M. J. Política pública e agricultura familiar: uma leitura do Pronaf. Estudos Sociedade e Agricultura, Rio de Janeiro, p. 70-82, 1997.

CONDRAF, Política de Desenvolvimento do Brasil Rural. Brasília, 2010.

CONTERATO, M. A. Dinâmicas regionais do desenvolvimento rural e estilos de agricultura familiar: uma análise a partir do Rio Grande do Sul. 2008. 290 f. Tese (Doutorado em Desenvolvimento Rural) - Faculdade de Ciências Econômicas, Universidade Federal do Rio Grande do Sul, Porto Alegre, 2008.

CONTI, B. M. e ROITMAN. F. B. Pronaf: uma análise da evolução das fontes de recursos utilizadas no programa. Revista do BNDES, Rio de Janeiro, n. 35, p. 131-168, 2011.

COPETTI, L. D. Fatores que dificultam o acesso dos agricultores familiares às políticas de crédito rural: o caso do Pronaf-Crédito no município de Alegria-RS. 2008. 206 f. Dissertação (Mestrado em Desenvolvimento Rural) - Faculdade de Ciências Econômicas, Universidade Federal do Rio Grande do Sul, Porto Alegre. 2008.

COSTA, V. G. Políticas públicas e agricultura familiar: uma avaliação do Pronaf em dois assentamentos rurais da Mata Sul Paraibana. 2013. 140 f. Dissertação (Mestrado em Desenvolvimento e Meio Ambiente) - Programa Regional de Pós-Graduação em Desenvolvimento e Meio Ambiente, Universidade Federal da Paraíba, João Pessoa, 2013.

DEPONTI, C. M. O processo de desenvolvimento rural à luz da perspectiva orientada ao ator: o caso da extensão rural brasileira. In: Congresso da Sociedade Brasileira de Economia, Administração e Sociologia Rural -SOBER, 2007. Londrina: Universidade Estadual de Londrina, 2007.

DIAS, A. F. Redistribuição e reconhecimento de gênero na perspectiva de Axel Honneth e Nancy Fraser. Saberes em perspectiva, Jequié, v. 2, n. 2, 2012.
DIEESE. Estatísticas do meio rural 2010-2011. 4. ed. São Paulo: DIEESE; NEAD; MDA, 2011.

DOMINGUES, A. P. Crédito Pronaf: conquista, afirmação e reconhecimento. O processo de formulação de uma política pública. 2007. 171 f. Dissertação (Mestrado em Administração Pública) - Escola Brasileira de Administração Pública, Fundação Getúlio Vargas, Rio de Janeiro, 2007.

ELLIS, F. Rural Livelihoods and Diversity in Developing Countries. Oxford: Oxford University Press, 273 p, 2000.

FETAEP. Federação dos Trabalhadores na Agricultura do Estado do Paraná. Cartilha de Orientação Pronaf Uma conquista dos trabalhadores rurais. Plano Safra 2013/2014. Disponível em: <http://www.fetaep.org.br/ Agricola/cartilha_pronaf_2013-2014.pdf $>$. Acesso em: dez. 2014.

FRASER, N. A justiça social na globalização: redistribuição, reconhecimento e participação. Revista Crítica de Ciências Sociais, v. 63, p. 7-20, 2002.

. Da redistribuição ao reconhecimento? Dilemas da justiça numa era "pós-socialista". Cadernos de campo, Tradução de Julio Assis Simões. São Paulo, n. 14/15, 2006.

GAZOLLA, M. e SCHNEIDER, S. Qual "fortalecimento" da agricultura familiar? Uma análise do Pronaf crédito de custeio e investimento no Rio Grande do Sul. Revista de Economia e Sociologia Rural, Piracicaba - SP, v. 51, p. 45-68, 2013.

. As duas "caras" do Pronaf: produtivismo ou fortalecimento da produção para autoconsumo? In: XLIII Congresso da Sociedade Brasileira de Economia e Sociologia Rural, Ribeirão Preto - SP. Anais..., CD Roan, 2005, 21p.

GRISA, C. Políticas públicas para a agricultura familiar no Brasil: produção e institucionalização das ideias. 2012. 280 f. Tese (Doutorado em Ciências) - Instituto de Ciências Humanas e Sociais, Universidade Federal Rural do Rio de Janeiro, Rio de Janeiro, 2012.

WESZ JUNIOR, V. J. e BUCHWEITZ, V. D. Revisitando o Pronaf: velhos questionamentos, novas interpretações. Revista de Economia e Sociologia Rural, Piracicaba - SP, v. 52, p. 323-346, 2014.

HONNETH, A. Luta por reconhecimento: a gramática moral dos conflitos sociais. Tradução de Luiz Repa. São Paulo: Ed. 34, 2003.

IBASE. Instituto Brasileiro de Análises Sociais e Econômicas. Relatório Pronaf - Resultados da etapa Paraná. 2006. Disponível em: < http://www.ibase.br/ 
userimages/pub_pronaf_final4.pdf $>$. Acesso em: jan. 2015.

IBGE. Censo Agropecuário 2006: agricultura familiar primeiros resultados. Rio de Janeiro: IBGE, 2009.

IPEA. Políticas sociais: acompanhamento e análise. Brasília: IPEA, 2007.

. Políticas sociais: acompanhamento e análise. Brasília: IPEA, 2008.

Políticas sociais: acompanhamento e análise. Brasília: IPEA, 2010.

Políticas sociais: acompanhamento e análise.

Brasília: IPEA, 2012.

Políticas sociais: acompanhamento e análise.

Brasília: IPEA, 2014.

LONG, N. e PLOEG, J. D. van der. Heterogeneidade, ator e estrutura: para a reconstrução do conceito de estrutura. Tradução: Rita Pereira, Daniela Garcez e Leandro Krug Wives. In: BOOTH, D. (ed.) Rethinking Social Development: theory, research and practice. England, Longman, 1994, p. 62-90. PGDR/UFRGS: Porto Alegre, 2009. (Versão para circulação interna). Disponível em: www.ufrgs.br/pgdr/arquivos/ipode_38. doc. Acesso em: set. 2015.

LUCAS, D. C. e OBERTO, L. C. Redistribuição versus reconhecimento: apontamentos sobre o debate entre Nancy Fraser e Axel Honneth. Direitos Culturais, Santo Ângelo, v. 5, n. 8, 2010.

MATTEI, L. Impactos do PRONAF: análise de indicadores. Brasília, Série Estudos 11 NEAD, Núcleo de Estudos Agrários e Desenvolvimento Rural/Ministério do Desenvolvimento Agrário, 2005.

Políticas de apoio ao desenvolvimento da agricultura familiar no Brasil: o caso recente do Pronaf. Revista Econômica do Nordeste, Fortaleza, v. 38, n. 1, 2007.

Análise da produção acadêmica sobre o Programa Nacional de Fortalecimento da Agricultura Familiar (PRONAF) entre 1996 e 2006. Estudos Sociedade e Agricultura, Rio de Janeiro, v. 18, n. 1, p. 56-97, 2010.

MATTEI, L. et al. Uma análise dos impactos do PRONAF sobre as economias locais nas regiões Nordeste, Sudeste e Norte do Brasil. In: Congresso da Sociedade Brasileira de Economia, Administração e Sociologia Rural - SOBER, 2007. Londrina: Universidade Estadual de Londrina, 2007.

MDA. Plano Safra da Agricultura Familiar 2000/2001 2014/2015. Brasília: Secretaria da Agricultura familiar. Disponível em: <www.mda.gov.br>. Acesso em: dez. 2014.
MENDONÇA, R. F. Dimensão intersubjetiva da autorealização - Em defesa da teoria do reconhecimento. Revista Brasileira de Ciências Sociais, São Paulo, v. 24, n. 70, 2009.

MERA, C. P. e DIDONET, G. B. Aplicação dos recursos do PRONAF pelos agricultores familiares do município de Cruz Alta (RS). Perspectiva Econômica, São Leopoldo, RS, v. 6, n. 2, p. 45-58, 2010.

NIEDERLE, P. A. A agricultura familiar entre o setorial e o territorial? Novos referenciais para as políticas de desenvolvimento rural no Brasil. Perspectivas Rurales, Universidad Nacional Costa Rica, Nueva Época, ano 12, n. 24, 2014.

. e GRISA, C. Diversificação dos meios de vida e acesso a atores e ativos: uma abordagem sobre a dinâmica de desenvolvimento local da agricultura familiar. Cuadernos de Desarrollo Rural, Bogotá, v. 5, n. 61, p. 41-69, 2008.

OLIVEIRA, C. et al. Participação e desenvolvimento: uma análise do perfil dos representantes do Conselho Municipal de Desenvolvimento Rural Sustentável de Diamantina, Minas Gerais. In: Congresso da Sociedade Brasileira de Economia, Administração e Sociologia Rural SOBER, 2008.

PEIXOTO, M. O Pronaf e o Plano Safra da Agricultura Familiar 2011/12: notas sobre a distribuição dos recursos. Boletim do Legislativo, n. 8, Núcleo de Estudos e Pesquisas do Senado, 2011.

PEREIRA, E. D. e NASCIMENTO, J. S. Efeitos do Pronaf sobre a produção agrícola familiar dos municípios tocantinenses. Revista de Economia e Sociologia Rural, Piracicaba - SP, v. 52, p. 139-156, 2014.

PEREIRA, L. G. T. C. Pronaf: política eficiente para resolver o problema dos agricultores assentados? In: XL Congresso Brasileiro de Economia e Sociologia Rural. Passo Fundo, RS. 2002. CD-ROM.

PERONDI, M. A. Diversificação dos meios de vida $e$ mercantilização da agricultura familiar. 2007. 239 f. Tese (Doutorado em Desenvolvimento Rural) - Faculdade de Ciências Econômicas, Universidade Federal do Rio Grande do Sul, Porto Alegre, 2007.

. e SCHNEIDER, S. Bases teóricas da abordagem de diversificação dos meios de vida. Revista de Desenvolvimento Regional, Santa Cruz do Sul, v. 17, n. 2, p. 117-135, 2012.

RESENDE. C. M. Desenvolvimento, reconhecimento $e$ redistribuição: uma análise do Programa Nacional de Fortalecimento da Agricultura Familiar. 2014. 95 f. Monografia (Graduação em Geografia) - Departamento 
de Geografia, Universidade Federal de Viçosa, Viçosa, 2014.

RODRIGUES, S. T. S. O crédito rural como promotor do desenvolvimento e o Programa Nacional de Fortalecimento da Agricultura Familiar (PRONAF). 2013. 208 f. Dissertação (Mestrado em Direito) - Programa de Pós-Graduação em Ciências Jurídicas, Universidade Federal da Paraíba, João Pessoa. 2013.

SCHNEIDER, S. Situando o desenvolvimento rural no Brasil: o contexto e as questões em debate. Revista de Economia Politica, v. 30, n. 3, p. 511-531, 2010.

- Teoria social, agricultura familiar e pluriatividade. Revista Brasileira de Ciências Sociais, São Paulo, v. 18, n. 51, 2003.

SCHNEIDER, S., CAZELLA, A. A. e MATTEI, L. Histórico, caracterização e dinâmica recente do Pronaf - Programa Nacional de Fortalecimento da Agricultura Familiar. In: SCHNEIDER, S., SILVA, M. C. e MARQUES, P. E. M. (Orgs.). Políticas públicas e participação social no Brasil rural. Porto Alegre: Ed. Universidade/UFRGS, p. 21-49, 2004.

SCHNEIDER, S. e GAZOLLA, M. Os atores entram em cena. In: . (Orgs.). Os atores do desenvolvimento rural: perspectivas teóricas e práticas sociais. Porto Alegre: Editora da UFRGS, 2011. p. 11-17.

SERENO, F. L. A influência do crédito do Programa Nacional de Fortalecimento da Agricultura Familiar (PRONAF) na percepção dos agricultores familiares do Distrito Federal. 2012. 126 f. Dissertação (Mestrado em Agronegócios)

- Faculdade de Agronomia e Medicina Veterinária, Universidade de Brasília, Brasília, 2012.

SOUZA, J. (Não) Reconhecimento e Subcidadania, ou o que é "ser gente"? Lua Nova, São Paulo, n. 59, 2003.
SOUZA, P. M. et al. Análise da evolução do valor dos financiamentos do Pronaf-Crédito (1999 a 2010): Número, valor médio e localização geográfica dos contratos. Revista de Economia e Sociologia Rural, Brasília, v. 51, p. 237-254, 2013.

TOLEDO, E. N. B. O Pronaf em Salvador das Missões: contradições de uma política de crédito. 2009. 190 f. Dissertação (Mestrado em Desenvolvimento Rural) - Faculdade de Ciências Econômicas, Universidade Federal do Rio Grande do Sul, Porto Alegre. 2009.

TOLENTINO, M. L. D. L. De qual rural fala o PRONAF? XXI Encontro Nacional de Geografia Agrária. Uberlândia, 2012.

. O (des)envolvimento no PRONAF: as contradições entre as representações hegemônicas e os usos dos camponeses. 2013. 277 f. Dissertação (Mestrado em Geografia Humana) - Faculdade de Filosofia, Letras e Ciências Humanas, Universidade de São Paulo, São Paulo. 2013.

TONNEAU, J. P., AQUINO, J. R. e TEIXEIRA, O. A. Modernização da agricultura familiar e exclusão social: o dilema das políticas agrícolas. Cadernos de Ciência e Tecnologia, Brasília, v. 22, n. 1, 2005.

VARGAS, D. L. Políticas públicas e diversidade na agricultura familiar: um estudo do Pronaf em Cachoeira do Sul/RS. 2012. 141 f. Dissertação (Mestrado em Extensão Rural) - Programa de Pós-Graduação em Extensão Rural, Universidade Federal de Santa Maria, Santa Maria, 2012.

VIEIRA, D. D. Identidade rural e agricultura familiar: o Pronaf B sob a ótica dos beneficiários. 2007. 152 f. Dissertação (Mestrado em Desenvolvimento Regional; Cultura e Representações) - Universidade Federal do Rio Grande do Norte, Natal, 2007. 